\title{
How to Improve the Diffusion of Climate-Smart Agriculture: What the Literature Tells us
}

\author{
Giulio Fusco ${ }^{1, *}$, Marta Melgiovanni ${ }^{2}$, Donatella Porrini ${ }^{1}\left[\right.$ and Traci Michelle Ricciardo ${ }^{1}$ \\ 1 Department of Economics and Management, University of Salento, Lecce, Italy, University of Salento, \\ 73100 Lecce LE, Italy; donatella.porrini@unisalento.it (D.P.); traci.ricciardo@unisalento.it (T.M.R.) \\ 2 Department of History, Society and Human Studies, Italy, University of Salento, 73100 Lecce LE, Italy; \\ marta.melgiovanni@unisalento.it \\ * Correspondence: giulio.fusco@unisalento.it
}

Received: 12 May 2020; Accepted: 22 June 2020; Published: 24 June 2020

\begin{abstract}
Climate-smart agriculture (CSA) is a technologically innovative response to the challenges faced by agriculture due to climate change. Its implementation needs a change of mentality in the direction of an approach that takes into account how the increase in technologically induced productivity affects climate change. In the belief that the in-depth analysis conducted by scientific research plays a fundamental role, we explore the characteristics, actors, and pillars of CSA, examining both the scientific literature and financed projects. Specifically, through a systematic review of the literature we address both the application and barriers to implementation at a global level, and then we focus on a case study of the geographical distribution of CSA projects in Europe. Our results show a heterogeneous framework in which we can note discrepancies among countries. Finally, as conclusive remarks, we consider the type of policies that could be implemented to improve the diffusion of CSA in the near future.
\end{abstract}

Keywords: smart agriculture; climate change; sustainability; literature review

\section{Introduction}

Today, almost one billion people will go to bed hungry. Following current estimates, the global population will increase by more than two billion by 2050 [1]. The agricultural sector plays a key role in economic development and the reduction of poverty in the world [2]. However, there are many threats to the agricultural sector, and one of the main ones is climate change and the consequent extreme events that have increased in recent years. In fact, many studies focus on the effects of climate change in reducing crop production, particularly in tropical and developing countries [3-5].

Climate change has an important impact not only on agricultural production, but also on food security. The climatic trends have been fairly rapid in many agricultural regions, with an increase in the level of atmospheric carbon dioxide $\left(\mathrm{CO}_{2}\right)$ and ozone $\left(\mathrm{O}_{3}\right)[6]$. Together with climate change, many factors will influence global food security in the next decades, such as changes in the rates of human population growth, income distribution, dietary preference, natural resources, demand for water and the frequency of natural disasters [7].

It is in this context that we analyze climate-smart agriculture (CSA) - "agriculture that sustainably increases productivity, enhances resilience, reduces greenhouse gases, and enhances achievement of national food security and development"- as it was presented and defined by the FAO at the Hague Conference on Agriculture, Food Security, and Climate Change, in 2010 [8,9].

If CSA emerges as a promising way to secure food for the growing world population under climate change conditions, its diffusion will depend on a change of mentality that provides for innovative 
practices and technologies, which promote agricultural productivity together with resilience to climate change and mitigation of greenhouse gas emissions [10].

For decades, investments in agriculture were intended to increase the productivity of smallholder farmers through technological developments, for example, irrigation infrastructures, assuming that this would be sufficient to stimulate agricultural intensification. We have experienced efforts to enhance food system productivity focused on a technology-push approach, assuming that significant productivity growth could be easily achieved through access to technologies. However, it is now necessary to change our view and consider that the way in which technologies are implemented must not overlook important issues such their impact on the climate.

Therefore, in this contribution, we follow an approach that takes into account that the in-depth analysis conducted by scientific research plays a fundamental role in that change of mentality that will push the diffusion of CSA in the near future. The starting point is the role of CSA as one of the most important factors in pursuing sustainable global development because it represents a set of strategies that can help increase the resiliency to weather events, adapt to climate change and decrease agricultural greenhouse gas emissions that contribute to global warming.

In this direction, in Section 2 we highlight the characteristics, actors, and pillars of CSA; in Section 3, we identify the geographical distribution of CSA literature in the world and the most relevant barriers to its adoption; Section 4 shows the relationship between scientific research and empirical projects in a European context; finally, the Section 5 considers how to address future policy interventions to improve the diffusion of CSA.

\section{The Definition of CSA in a General Framework}

Looking at the literature, as far as the general content is concerned, on the one hand, we find those contributions useful in defining CSA in theoretical terms, concepts or policy; and on the other, we find those focused on the diffusion of CSA in various geographic and socio-economic contexts.

Following Totin et al. [11], generally, in the literature, the topic can be traced back to three pillars: (1) agronomic and economic productivity, (2) resilience and adaptive capacity, and (3) climate change mitigation.

For what concerns the first pillar, CSA aims to sustainably increase agricultural productivity and incomes from crops, livestock, and fish without having a negative impact on the environment. This, in turn, will raise food and nutritional security. A key concept related to raising productivity is sustainable intensification by increasing food production from existing farmland while minimizing pressure on the environment.

This first pillar is strongly connected to the second one, based on the facts that adaptation can reduce vulnerability by altering the exposure, reducing sensitivity and increasing adaptive capacity. There are various adaptation strategies that can be considered when planning agriculture interventions. All adaptation strategies are based on a combination of specific actions (e.g., switching from one crop variety to another) and systemic changes (e.g., diversifying livelihoods against risks or institutional reform to create incentives for better resource management). Adaptation strategies include a broad set of activities ranging from activities that focus on reducing drivers of vulnerability to interventions aimed at confronting not yet experienced climate change impacts.

The third pillar considers the reduction of agriculture's contribution to climate change (mitigation). Mitigation activities promote efforts to reduce or limit GHG emissions or to enhance GHG sequestration, including technological changes that reduce resource inputs and emissions per unit of output. There are three major options to mitigate climate change: reducing emissions; avoiding or displacing emissions; removing emissions.

Given these three pillars of CSA function at diverse geographic, spatial, economic and institutional levels, the relative importance of one pillar over another is influenced by context, scale and ideologies and this makes it difficult to arrive at a single global definition. However, it is generally agreed that in 
order to be successful in sustainability and achieve climate resilience and food security, CSA needs to take a flexible approach, working with the various narratives, instead of working around them [12].

Although generally speaking, CSA should be considered as the union of the three aforementioned pillars-however, this is not always the case in the literature where we find that the focus may be on a single pillar or a combination of only two, often depending on the geographical context where the research takes place.

The first pillar "productivity" aims at sustainably increasing agricultural production, thereby contributing to food security and higher-incomes without damaging the environment [11]. As an example, in 2015, Alem et al. [13] addressed the issue of productivity discussing an alternative method of rice farming in Tanzania that requires less water consumption and does not require the flooding of the fields, and therefore, leads to lower methane emission. The authors argue the need for greater institutional intervention so that these smallholder farmers may be guaranteed profitability.

The second pillar "adaptation", or building resilience to climate change and variability, is the focus of the editorial of Siedenburg et al. [14], although it clearly states the advantages of the combination of the three pillars. In particular, they discuss small farmers and the need for financial incentives to aid in the implementation of CSA adaptation strategies, which in turn, would contribute to a win-win by including positive effects for mitigation. Another study that addresses adaptation is the one written by Fader et al. [15] where the aim is water scarcity in Southern and Eastern Mediterranean countries and the need to implement more effective irrigation systems.

Finally, "mitigation", the third pillar, is the reduction or removal of greenhouse emissions where possible, by avoiding deforestation and using agricultural methods with lower gas emissions. Through Low Emissions Technology (LED), the emission reduction is based on the difference of emissions between those using conventional agricultural practices compared to those of new CSA practices. LED places human needs, such as food, before mitigation, and therefore, pinpoints agricultural development goals first and successively the mitigation applications through which to attain them [16].

We should point out that most of the studies focusing solely on mitigation come from high-income countries. For example, Böttcher et al. [17] on the topic of mitigation, debate the choice of land management as a means to mitigate climate change. In particular, they study the forest region of Thuringia to establish priorities in land management in order to choose the best options for both economic gain and mitigation of $\mathrm{CO}_{2}$ emissions.

As previously mentioned, while CSA ideally aims at all three objectives, this does not necessarily mean that every single practice put into action will attain a "triple win". In fact, although CSA calls for the consideration of the three pillars collectively, this must be done taking into account various factors, including the local situation [18].

Moreover, in literature, the chosen focus generally depends on the level of development reached in the countries in the object. Typically, we find that studies that concentrate on the adaptation and/or productivity pillars come from countries with low to lower middle income; whereas, the ones focusing on mitigation, as mentioned above, tend to come from high-income countries [11].

Despite the signing of international agreements such as the global alliance for climate-smart agriculture (GACSA), launched at the United Nations Secretary General's Climate Summit in September 2014, with the goal of helping 500 million smallholder farmers practice CSA, there are still controversies about CSA application [19].

In fact, even if there is greater clarification regarding the theoretical definition of the concept and methodology for its application, controversies over CSA still persist, especially those related to the role of agricultural mitigation and its financing in developing countries, as well as those concerning the development and deployment of technologies for agricultural development. Also, CSA should be considered as a general instrument to identify locally appropriate solutions to manage agriculture for sustainable development and food security under climate change, rather than a catchall tool. 
As we will see, these controversies are highlighted in the literature, while, in the meanwhile, supranational bodies such as the European Union are investing in CSA in order to support member states in developing sustainable economic strategies, as will be analyzed in the next sections.

\section{The Literature on CSA and the Barriers for its Diffusion}

In the belief that the in-depth analysis conducted by scientific research plays a fundamental role, we explore the characteristics, actors, and pillars of CSA, examining the scientific literature. Particularly, in this section, we present a structured analysis of the literature based on the main sources of research methodology in Social Sciences [20].

\subsection{Methodology}

In order to understand the general level of knowledge and research about CSA in the literature, we conducted a study using the systematic review framework proposed in Berrang-Ford et al. [21], which provides guidelines and formats for synthesizing and tracking climate change adaptation research.

Then, we carried out a revision protocol to ensure the replicability and verification of the results. The protocol establishes the principles of the homogeneity and functionality of the sources compared to the knowledge, as well as the criteria and tools for selecting the sources. Among the inclusive criteria we identified:

(1) A predominant search term ("Smart Agriculture") and other search criteria ("adaptation", "mitigation", "policy");

(2) A time period of publication between 2009 and 2019;

(3) The publication type, such as article, review, or book chapter;

(4) English as the language of publication.

"Web of Science" and "Scopus" were chosen as the search engines due to their size and the number of results they provide, offering the researcher a complete overview of easily investigable contributions.

To carry out a relevant literature review of CSA, we initially used the search term "Smart Agriculture", and then we combined it with the more specific terms: adaptation, mitigation and policy.

In our study, we decided not to include the so-called "grey literature", and we based the results of our work only on the analysis of peer review scientific literature.

The preliminary search produced 479 results from Scopus and 377 from Web of Science, which were then exported using the software ENDNOTE X7 [22] for an initial screening. Successively, we removed the duplicates and publications that were not articles, books, reviews, conference papers, or editorial material and 445 publications remained. Finally, after screening the titles and abstracts based on our criteria, 198 publications remained relevant. Table 1 shows the criteria that we used in our preliminary search.

Table 1. Inclusion and exclusion criteria for literature selection.

\begin{tabular}{cc}
\hline Inclusion Criteria & Exclusion Criteria \\
\hline Text in English & Text in languages other than English \\
\hline $\begin{array}{c}\text { Publication type is article, review, } \\
\text { or book chapter }\end{array}$ & Publication type is different \\
\hline Linked to the agricultural sector & Linked to other sectors \\
\hline $\begin{array}{c}\text { Published in the period (2009-2019) } \\
\text { (economic, institutional, behavioral, } \\
\text { organizational, market) }\end{array}$ & Published in other periods \\
\hline
\end{tabular}


Then, we performed a full-text review of the 198 publications to confirm that these studies were compatible with our scope, verifying if the papers included sufficient details for our specific research objective.

The final list contained 26 publications out of 856 possible initial results, based on the aforementioned criteria. The reasons for excluding all the other publications were the following: (1) They did not respond to the research question; (2) they were published in different time periods other than the one chosen; (3) they were published in a language other than English; (4) they were not published or not available entirely for online consultation.

Through an investigation of the content of the selected contributions, the qualitative reading of the selected codified results led to the elaboration of a summary of the contents of each contribution. In this way, it was possible to understand the narrative evolution of the object of study and to detect gaps in the knowledge, critical issues, and new approaches.

\subsection{Results}

Therefore, the final systematic literature review focused on 26 documents (two of which are working papers, while the other 24 are papers that have been published in academic journals).

First, an analysis of the keywords in the literature was carried out, since the main interest of authors concerns the role of CSA in the adaptation, mitigation and innovation of the agriculture system. In fact, CSA is considered a path for the challenges faced by agriculture and the sector is closely linked to the food security issue.

The sample was analyzed through different approaches. The first approaches used were temporal and spatial ones. In fact, for the period 2009-2019, an examination was carried on the number of studies that discuss the topic of CSA and its limitations, and the location of the different authors in the world.

Figure 1 shows the frequency of the studies in the period considered.

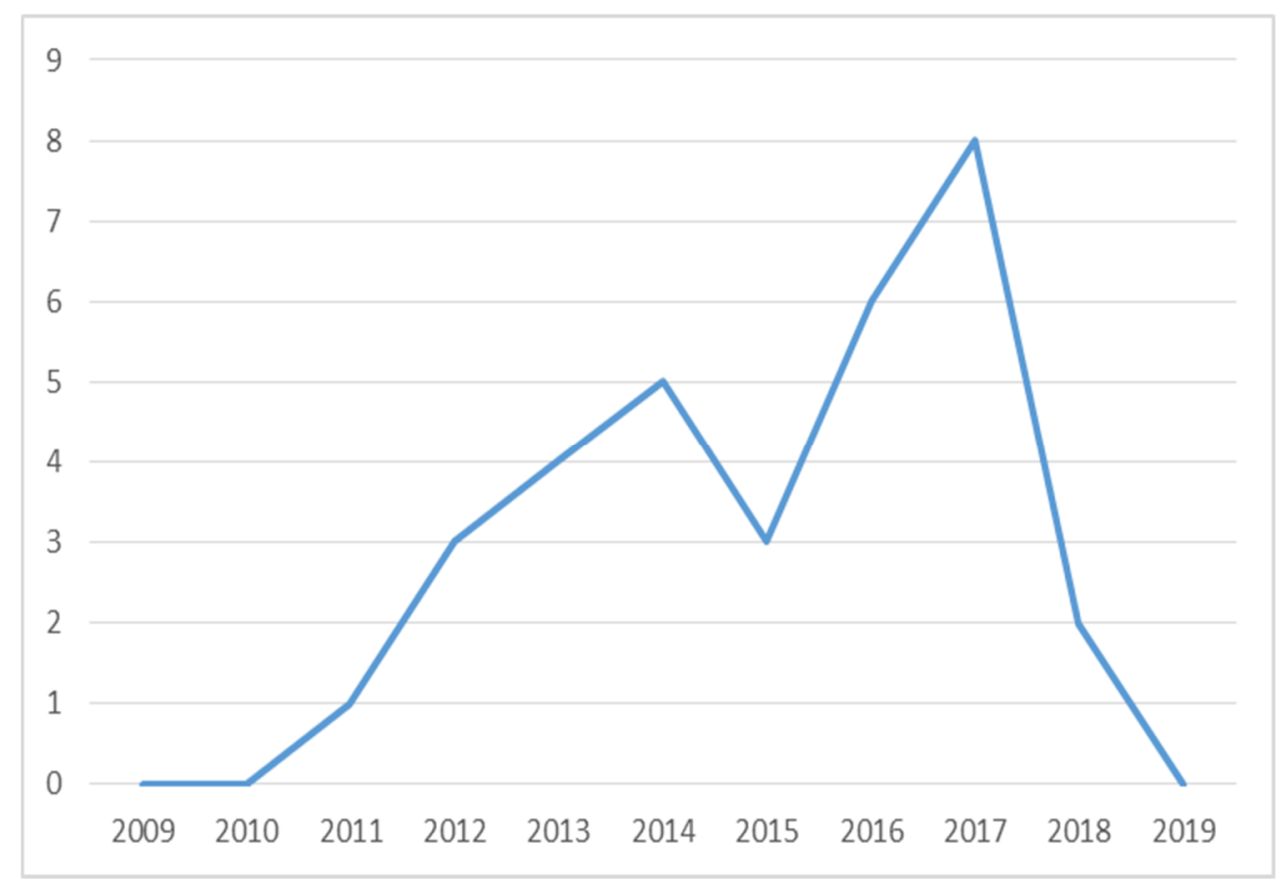

Figure 1. Frequency of the studies (2009-2019).

In the Figure 1, we can see that the greatest number of publications is in 2017, whereas, in 2009 and 2010 there are none. Twenty-two studies on this topic are concentrated in the years 2014-2017. This high number shows that during these years, much more research activity was carried on the application of the CSA. The result indicates a high concentration of studies in a given period of time 
and gives the idea of great scientific interest in the field, probably connected with the debate about climate change and the role of agriculture.

In Figure 2, the geographical distribution of the authors by country of origin is considered.

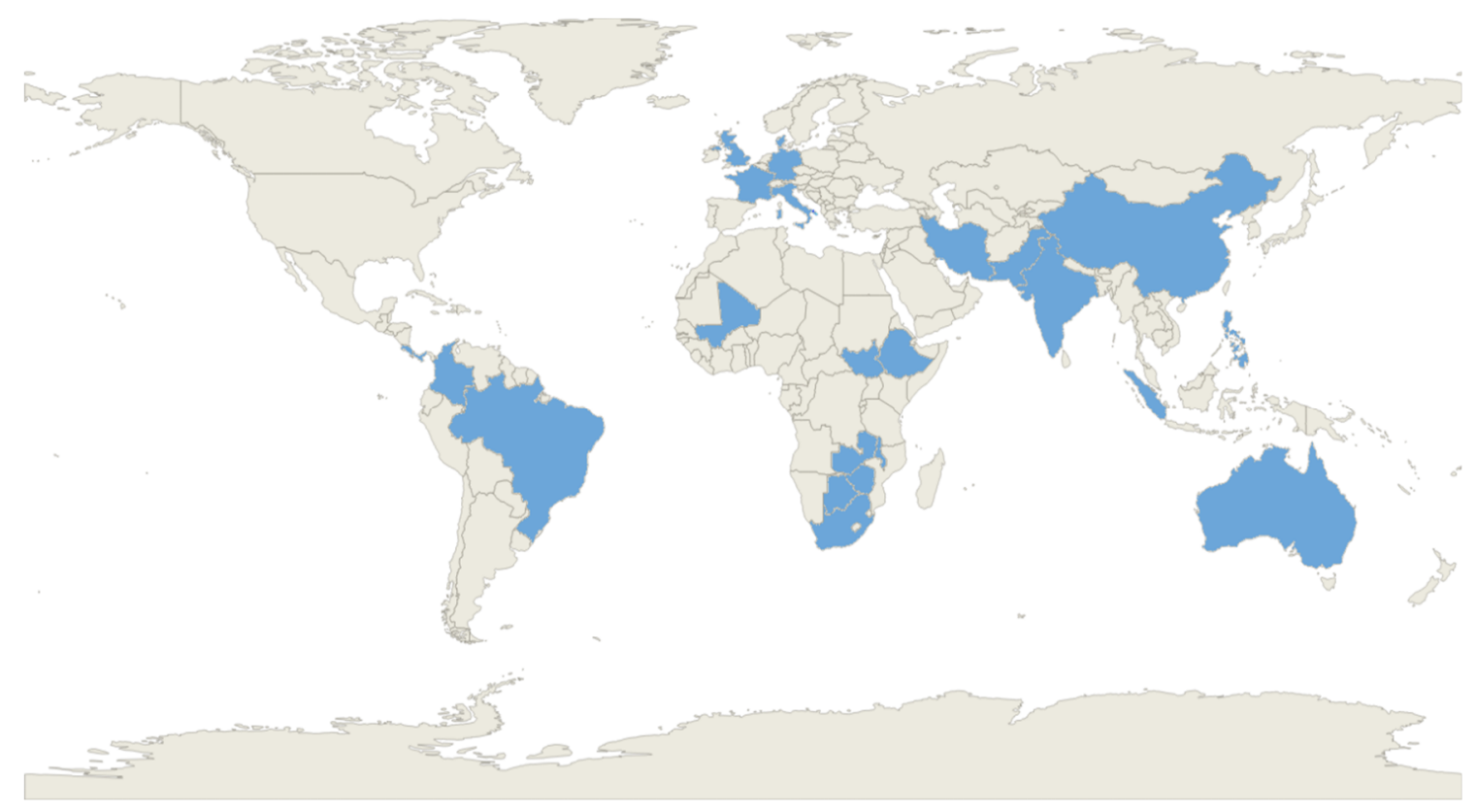

Figure 2. Distribution of the authors on climate-smart agriculture (CSA) in the world.

The results, illustrated in Figure 2, show widespread coverage of all the continents (excluding North America) - not only in Europe, but also with many authors from South-East Asia, South-East Africa, and South America. The concentration in a given period of time, as in Figure 1, combined with the widespread diffusion all over the world, as in Figure 2, allows us to consider our sample of studies representative of a specific, and at the same time global, interest in the topic by the scientific community.

Given the above results, we carried out another research target that regards the identification of the key barriers to the adoption of pro-environmental technological innovations, particularly CSA technologies. We started from the definition of the research questions that can be summarized in these terms: What are the basic barriers to the adoption of climate-smart agriculture instruments? What are the possible policy solutions?

Previous studies have analyzed the barriers to the adoption of pro-environmental technologies, generally in the agriculture sectors [21]. The main barriers were identified and grouped based on the systematic literature review [11]. However, the originality of our contribution is the focus specifically on the barriers to the practical application of CSA tools.

We concentrated on the several barriers mentioned as relevant in the adoption and diffusion of CSA technology by the previous literature. In particular, based on the classification of Long et al.'s [23] five categories, were identified: economic, institutional, behavioral, organizational and market, as summarized in Table 2 . 
Table 2. Overview of barriers to adoption of CSA based on the literature review.

\begin{tabular}{|c|c|c|}
\hline Barrier Type & Barrier Specification & Source \\
\hline Economic & $\begin{array}{c}\text { High initial cost } \\
\text { High Implementation cost } \\
\text { Hidden cost (transactional cost) } \\
\text { Uncertain returns and results } \\
\text { Poor Access to Capital } \\
\text { Temporal asymmetry between costs and benefits } \\
\text { Long pay-back periods (ROI) } \\
\text { Over discounting the future }\end{array}$ & $\begin{array}{c}\text { McCarthy et al. [24]; Bogdanski [25]; } \\
\text { Siedenburg et al. [15]; Neufeldt et al. [26]; Harvey et al. [27]; } \\
\text { Lipper et al. [18]; Steenwerth et al. [7]; Wright et al. [28]; } \\
\text { Peterson [29]; Rosenstock et al. [30]; Ampaire et al. [31]; } \\
\text { Long et al. [23]; Zougmoré et al. [32]; } \\
\text { Rosenstock et al. [33]; Engel [34]; } \\
\text { Khatri-Chhetri et al. [35]; Chandra et al. [12]; Lee [36]; Sain et al. [37]; Andrieu et al. [38]; } \\
\text { Westermann et al. [39]; Senyolo et al. [40]; }\end{array}$ \\
\hline Institutional & $\begin{array}{l}\text { Low institutional support } \\
\text { Lack of regulatory framework } \\
\text { Policies and Institutions }\end{array}$ & $\begin{array}{l}\text { Scherr et al. [41]; Bogdanski [25]; Neufeldt et al. [26]; } \\
\text { Harvey et al. [27]; Lipper et al. [18]; Wright et al. [28]; } \\
\text { Ampaire et al. [31]; Zougmoré et al. [32]; Dougil et al. [42]; } \\
\text { Chandra et al. [12]; Andrieu et al. [38]; Senyolo et al. [40]; }\end{array}$ \\
\hline Behavioral & $\begin{array}{l}\text { Results/effects of technology difficult to observe } \\
\text { Conflict with traditional methods } \\
\text { Farmers' beliefs and/or opinions } \\
\text { Farmers' level of education } \\
\text { Lack of management support/awareness }\end{array}$ & Neufeldt et al. [26]; Harvey et al. [27]; Steenwerth et al. [7]; Peterson [29]; Khatri-Chhetri et al. [35]; Senyolo et al. [40] \\
\hline Organizational & $\begin{array}{c}\text { Poor information } \\
\text { Inability to assess technologies } \\
\text { Lack of required competencies/skills required to use } \\
\text { technologies }\end{array}$ & $\begin{array}{c}\text { Scherr et al. [41]; Neufeldt et al. [26]; Lipper et al. [18]; } \\
\text { Steenwerth et al. [7]; Rosenstock et al. [30]; } \\
\text { Ampaire et al. [31]; Long et al. [23]; Zougmoré et al. [32]; } \\
\text { Rosenstock et al. [33]; Engel [34]; Dougil et al. [42]; Chandra et al. [12]; Senyolo et al. [40]; }\end{array}$ \\
\hline Market & $\begin{array}{c}\text { Uncertainty } \\
\text { Poor information } \\
\text { Lack of market attractiveness } \\
\text { Market not aligned to preferences }\end{array}$ & $\begin{array}{c}\text { McCarthy et al. [24]; Bogdanski [25]; Rosenstock et al. [30]; } \\
\text { Brandt et al. [43]; Lee [36]; Scherer et al. [44]; } \\
\text { Westermann et al. [39]; }\end{array}$ \\
\hline
\end{tabular}


Examining Table 2, it can be seen that, in particular, the economic barriers are well represented in literature: Many researchers have highlighted how the cost of technological innovation is prohibitive, especially in the first step of the process, also due to the difficulty in finding capital [23-25,27,30,32,35,39]. Where the economic barriers are low or have been overcome, literature outlines other types of barriers that prevent the diffusion of climate-smart agriculture.

In some cases, there is a behavioral limitation, which can be manifested in the refusal of the farmer to accept new technologies, due to his education and/or beliefs $[7,26,27,29,35,40]$.

In still other cases, the main limitation that prevents CSA adoption are either institutional and organizational barriers. In the former, all cases in which the institutions do not support the adoption of new technologies through specific laws or aid were included [12,27,31,32,38,41,42]. Whereas, Organizational barriers encompass those limitations that farmers have in their own organization, such as the "inability to assess technologies" where it is difficult to introduce CSA into the production process or where there is not a sufficient level of knowledge [18,23,34].

Finally, the last key barriers in this analysis are the market barriers, which include all cases where the farmers are in the condition to apply new technologies, but they are limited due to the market reaction $[24,25,36]$.

Figure 3 represents the frequency distribution of the barriers in the literature for the period considered in this research.

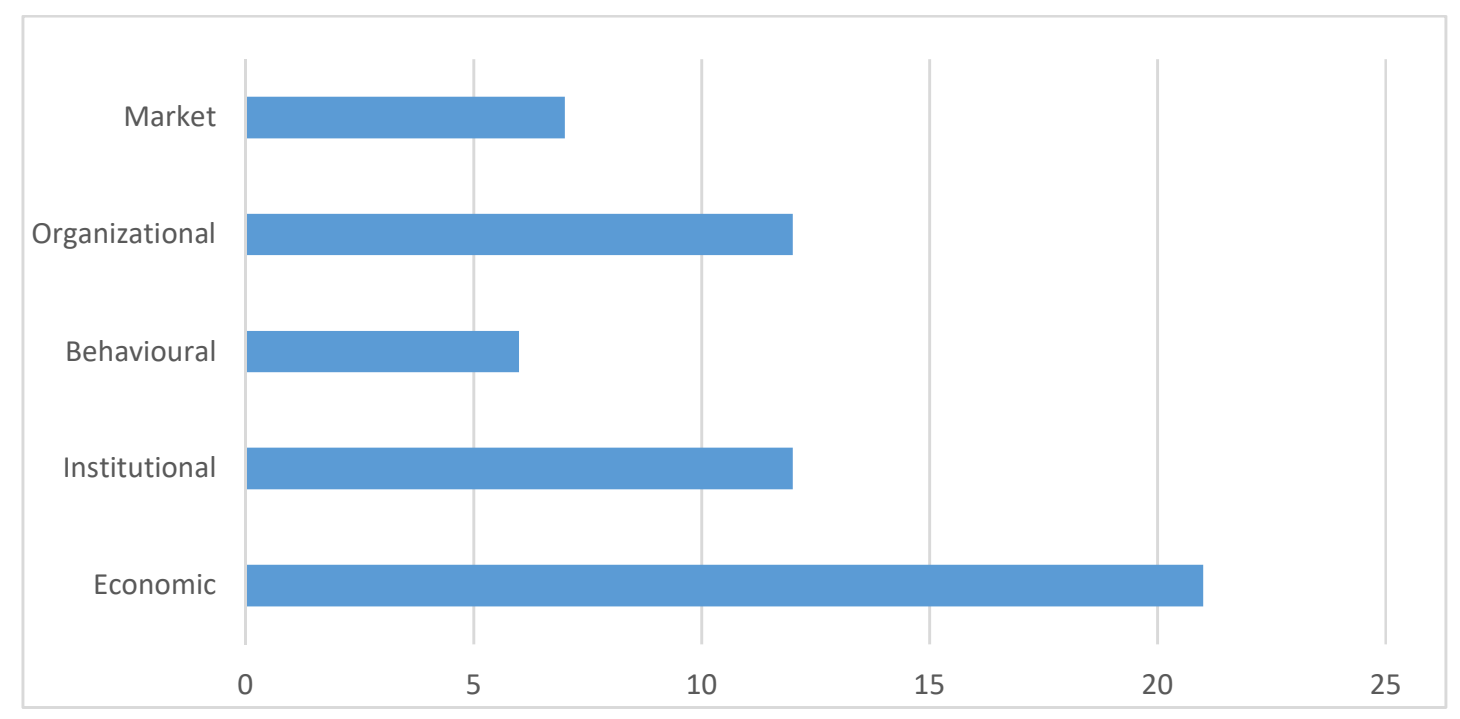

Figure 3. Frequency of distribution of the barriers (2009-2019).

As can be seen from Figure 3, the three main barriers highlighted by the literature in our selection are the Economic ones, followed by the institutional and organizational ones. In practice, economic barriers correspond to high initial and implementation costs, the presence of transactional costs, the uncertainty of returns and results and the difficulty in accessing capital. Institutional barriers indicate low participation and support from stakeholders, taking into consideration that fundamental support for the success of CSA comes from civil society, local institutions, government and non-governmental organizations among other stakeholders [45]. Finally, Organizational barriers are those limitations that farmers have in their organization as diversity in people's culture, and their socio-economic conditions [46].

The analysis of the barriers proposed above can also be subject to verifications referring to a specific geographical area. Long et al. [23], particularly, presented a theoretical framework based on a literature review of socio-economic barriers affecting adoption and diffusion. This framework is explored through data from semi-structured interviews with CSA technology providers and members of agricultural supply chains, such as farmers' associations and consumer goods producers (the end-users of the technology) in the Netherlands, France, Switzerland, and Italy. 
With the idea that the factors that appear to be the main obstacles to the diffusion of CSA call for effective policies that give economic incentives and support for CSA diffusion, in the next section, we present an analysis of the implementation of a public policy instrument, such as project financing, by a public institution in a homogeneous geographical area. In this direction, we analyze the activities by the European Commission to finance projects for the implementation of CSA within the European countries.

\section{An Analysis of the European Financed Projects}

When analyzing the actions that can contribute to the improvement of the diffusion of CSA, taking into account the above results in terms of the relevance of the economic barriers, it is important to have a look at the activities for the project financing. In this section, we check empirically to verify whether or not the barriers outlined in the analysis of the literature are present in the European context. To test this aspect, we analyze the case of the European projects, with specific attention focused on the countries involved as coordinators in the numerous programs (H2020, FP7, CIP).

Europe has always had a great agricultural vocation, which today has led to a prominent position in the world for quality agricultural production. The Old Continent stands out for its attempts to reconcile the needs of an increasingly competitive global market with the socio-economic needs of the communities and the environmental constraints that occur on a local level.

The political framework within which the actions of all the Member States are inscribed is the CAP (Common Agricultural Policy) launched in 1962 and based on two pillars (1. direct payments to farmers; 2. development of rural areas). It underwent profound transformations throughout the 1990s and 2000s, until reaching a more holistic vision in 2013, which was increasingly based on an integrated sustainable approach to resources functional to the development and well-being of rural areas.

Currently, the European Commission's orientation is towards supporting sustainable and resilient agriculture based on research and innovation [47]. In fact, it pushes Member States to invest in CSA by illustrating the benefits that derive from smart agriculture. However, as we will see, there is a certain heterogeneity among the various countries in terms of the use of the funds (European Structural Investment Funds), through which the CAP is financed and implemented.

To analyze the diffusion of CSA, we use a collection of data regarding the European projects for the period 2009-2019. The research was conducted consulting the institutional site called Community Research and Development Information Service [46]. In the final selection, we utilized as a key phrase "climate-smart agriculture", and we included the following information:

(a) Project acronym;

(b) Years of the project (between 2009-2019);

(c) Organization country;

(d) Domain of application (food and natural resources, climate change and environment).

The results obtained included a total of 74 projects for an initial screening. We then removed the projects regarding sectors different than agriculture, such as fishing, manufacturing, etc. and contexts other than agricultural land, excluding, for example, coastlines and fisheries. Moreover, we excluded any projects concluding after 2019, as well as those that began before 2009, even if partially conducted during our timeline. The final list included 36 projects.

Our final selection of 36 projects shows a concentration of activity in the biennial period 2016-2018, that is, the time during which discussions regarding the future (post-2020) of the CAP are the most intense-including the Cork 2.0 Conference and other occasions, in which the importance of aiming efforts at the introduction of precision technologies and innovation in the agricultural sector, as well as the strengthening of agricultural insurance and all tools in order to stabilize agricultural income (COM (2016) 0605) is confirmed. 
The European interest for these topics is evident in the Result Pack of precision agriculture, established by the same European Union [48].

In Figure 4, we present the assessment of 12 projects (ECHORD PLUS PLUS, SWEEPER, VINEROBOT, FIGARO, SYMPHONY, AGROIT, FOODIE, AUDITOR, 4D4F, IoF 2020, RECAP, SMART AKIS), with the exception of IoF 2020 because it has not been completed yet (see Appendix A for a specific description of the projects). The recipients of the projects are European farmers and breeders, local communities, small and medium-sized enterprises that contribute to the protection of biodiversity and the development of territories with their work.

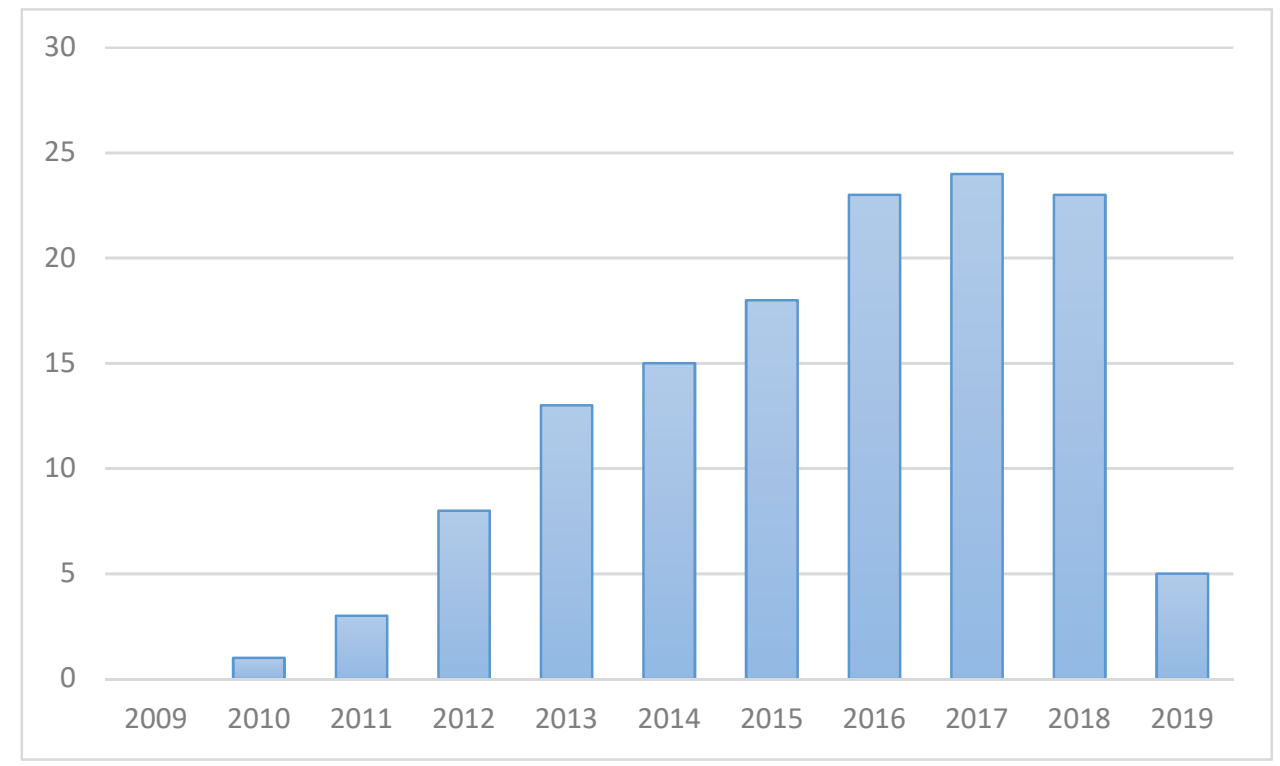

Figure 4. The number of financed European projects (2009-2017).

Figure 4 shows a clear increasing trend in the number of financed projects from 2009 to 2017. It is useful to consider that the objectives of these projects mainly concern the introduction of technological innovation (robotics, sensors, big data, cloud computing) in all phases of the cultivation cycle, from soil preparation to harvesting. Only two projects (RECAP and SMART AKIS) concern support for human capital and in particular, the exchange of information between stakeholders to promote better understanding and compliance with regulations and policy.

For our purpose, it is interesting to analyze which countries were involved as coordinators of the European projects, as in Figure 5.

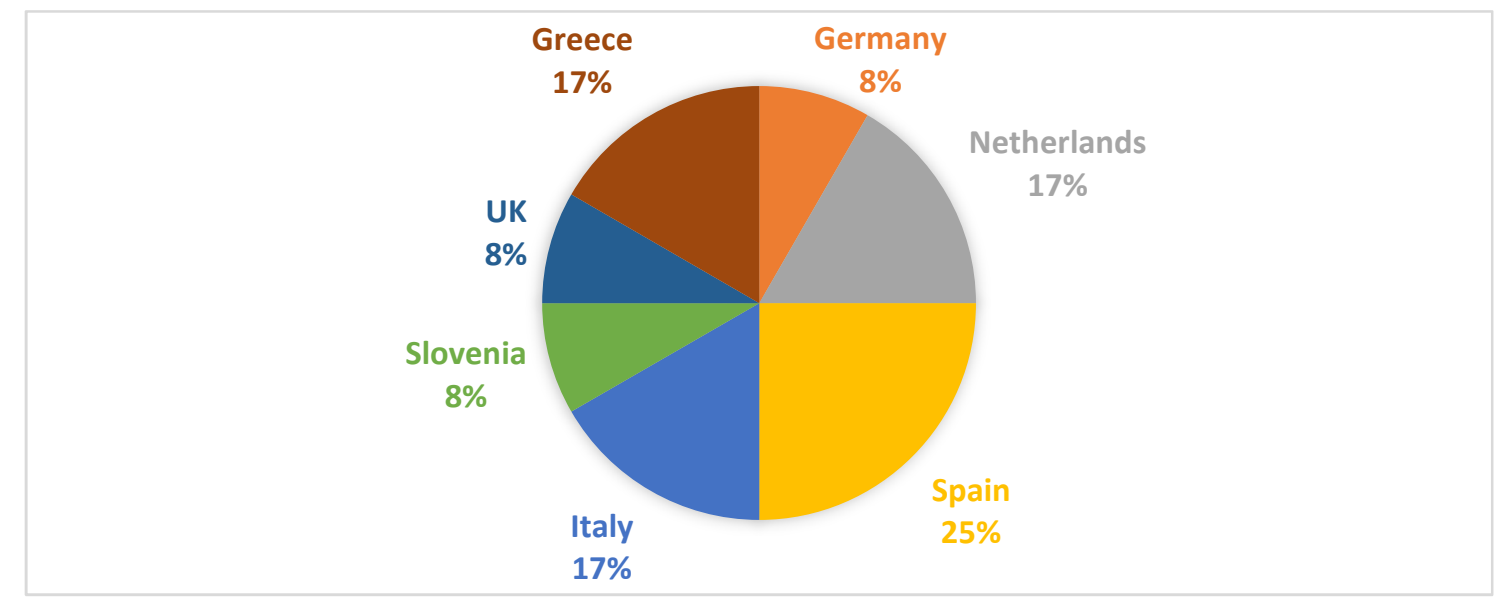

Figure 5. Countries involved as coordinators of the European projects. 
We can notice that the countries more involved as coordinators (Spain, Italy, the Netherlands, Greece) are those historically characterized by a strong agricultural vocation.

These countries include: Italy, which is the first country in Europe for added value infact almost a fifth of the added value of the entire EU agricultural system has been generated (out of an estimated 188.7 billion euros in 2019, Italy contributed 16.8\%) [49]; Spain, which is among the first countries for the number of farms on a regional basis [50]; the Netherlands, which is the leading European country for the exportation of agricultural products [50], and investment in innovative technology to help contrast its adverse geomorphological conditions, with a third of the country being under sea level; and Greece, which, thanks to its economy being anchored to the primary sector, was able to avoid high levels of unemployment in its rural areas-on the contrary to the urban ones-during the 2008 financial crisis, the effects of which can still be seen in the economy and on the country as a whole [51].

We can add to this list Germany, which, together with Spain and Italy, generates the majority of the standard output by agriculture across Europe, and the United Kingdom, among the top 5 recipients of European direct payments, at least up until Brexit, which will likely change the fate of farmers [50], and finally, Slovenia where the model of family farming represents its strength because of market stability, but also its weakness because of the great digital divide to overcome and the low social inclusion to defeat, as defined by the European Network for Rural Development (ENRD).

It is also interesting to analyze which countries were involved as partners of the European projects, as seen in Figure 6.

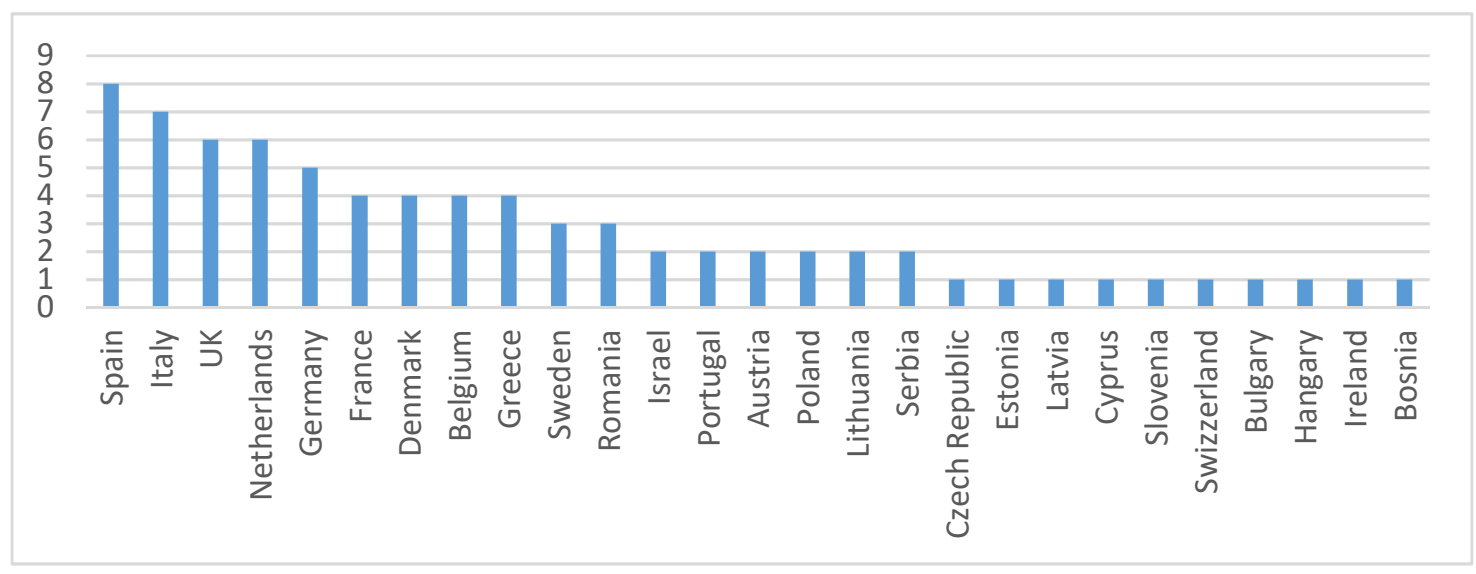

Figure 6. Countries involved as partners in European projects.

Considering the role in the market and the contribution to the wealth, as Eurostat highlights, countries with high involvement are those few that have intensive agricultural production, generating most of the economic value (Spain, Italy, the Netherlands, Germany, France, Denmark, Belgium). These are additional to the Greek economy, which as we have already seen, is firmly anchored in agriculture.

More than 15 countries have medium-low participation in projects. Among these, we note emerging countries from Eastern Europe with a raw milk and meat production that has increased in recent years and others from Central-Northern Europe with a concentration of harvested production. All these countries, and Portugal too, have a great number of farms yet do not generate an important value deriving from agriculture, probably because they are characterized by an extensive production. 


\section{Conclusions}

This research was conducted in the belief that in the future we will need more and more climate-smart agriculture to support sustainable and equitable transitions for agricultural systems and livelihoods across scales, due to the increasing attention on economic development, the reduction of poverty and food security. In fact, CSA guides both stakeholders and policymakers to meet the challenges presented. To do this, they must implement changes, and adjust the agricultural and food systems, to achieve the set sustainability goals.

Our research focused first of all on an analysis of the scientific studies regarding CSA in the world, finding an increasing trend that ended in 2017, and there was a concentration in South East Asia, South East Africa and South America, besides in Europe. We then sought to identify the barriers inhibiting the practical application of CSA as an answer to the imperative of agriculture undergoing a transition to adapt to the impacts of climate change and adjust to the demands associated with climate mitigation objectives. By undertaking this assessment, according to Schaafsma et al. [52], the results have illustrated that the key barriers are economic ones. We then moved on to the projects financed by the European Commission in the decade from 2009 to 2019, and found that there was an increasing trend until 2017. We also found that the countries involved were the ones with agricultural vocations and the strongest economies. In turn, this allowed for discussion on provisional activities and policy measures that may need to be enacted in order to enhance and boost the adoption of CSA.

Just to highlight a potential limit of our methodology choices, we could also have considered other search criteria, such as "conservation agriculture", "agroforestry", etc., as direct examples of the application of climate-smart agriculture. In this case, the number of countries involved, and the number of projects would increase significantly, and the presentation of climate-smart agriculture would be more realistic. It is our intention to address this research objective in the future.

From our review of the literature, it emerges that the economic barriers, such as high costs and the difficulty of finding capital, are the main limits to the diffusion of CSA. However, some other factors have not been considered in the existing literature, such as the importance of institutions in the uptake of CSA technologies (e.g., market) and the engagement of the private sector in agricultural development. Another limitation can be found in the link between the three pillars and the contextual factors. Moreover, a low number of empirical papers deal with this topic, due to the difficulty in obtaining available data in order to measure the suitability and benefits of CSA activities.

What emerges is the conclusion that a well-defined policy and institutional framework will not only help farmers in successfully adopting CSA innovations, but it will also help support the stakeholders in order to facilitate this process. In addition, good policy and institutional framework can minimize the farmer's challenges, reducing the CSA adoption constraints, and enhancing sustainability in scaling processes [45].

In conclusion, given that technology-oriented interventions alone may not be enough to achieve sustainable agricultural transformation, this research goes in the direction of highlighting the need to promote the financing of new projects and new investments in order to enhance and boost technological innovation for CSA.

Author Contributions: All authors contributed to every part of the manuscript. All authors have read and agreed to the published version of the manuscript.

Funding: This research received no external funding.

Conflicts of Interest: The authors declare no conflict of interest. 


\section{Appendix A}

Table A1. Title and Description of European Projects

\begin{tabular}{lll}
\hline Project Abbreviation & Project Title & Description \\
\hline ECHORD PLUS PLUS & $\begin{array}{l}\text { European Clearing House for Open } \\
\text { Robotics Development Plus Plus }\end{array}$ & robotics for vegetable harvest \\
\hline SWEEPER & Sweet Pepper Harvesting Robot & robotics for vegetable harvest \\
\hline VINEROBOT & Vine Yard Robot & robotics for wine production \\
\hline FIGARO & $\begin{array}{l}\text { Flexible and Precise Irrigation Platform to } \\
\text { Improve Farm Scale Water Productivity }\end{array}$ & irrigation technology, DSS \\
\hline \multirow{2}{*}{ SYMPHONY } & $\begin{array}{l}\text { Integrated System Based on Photonic } \\
\text { Microresonators and Microfluidic } \\
\text { Components for Rapid Detection of } \\
\text { Toxins in Milk and Dairy Products }\end{array}$ & sensors for dairy producers \\
\hline AGROIT & Advanced Farm Management & virtual platform, app \\
\hline FOODIE & Farm-oriented Open Data in Europe & cloud computing \\
\hline AUDITOR & $\begin{array}{l}\text { Advanced Multi-Constellation EGNSS } \\
\text { Augmentation and Monitoring }\end{array}$ & GNNS ground based augmentation system \\
\hline 4D4F & Internet of Food and Farms 2020 & mapping, sensor for agri-food \\
\hline IoF 2020 & Data Driven Dairy Decisions for Farmers & technology for breeders \\
\hline RECAP & Reinforcing CAP & big data to improve CAP, respect of law \\
\hline SMART AKIS & Smart Farming Thematic Network & information about new technology in agriculture \\
\hline
\end{tabular}

\section{References}

1. Faurès, J.M.; Bartley, D.; Bazza, M.; Burke, J.; Hoogeveen, J.; Soto, D.; Steduto, P. Climate Smart Agriculture Sourcebook; FAO: Rome, Italy, 2013; Volume 557, Available online: http://www.fao.org/climate-smartagriculture-sourcebook/en/ (accessed on 25 January 2020).

2. Christiaensen, L.; Demery, L.; Kuhl, J. The (evolving) role of agriculture in poverty reduction-An empirical perspective. J. Dev. Econ. 2011, 96, 239-254. [CrossRef]

3. Lobell, D.B.; Schlenker, W.; Costa-Roberts, J. Climate trends and global crop production since 1980. Science 2011, 333, 616-620. [CrossRef] [PubMed]

4. Knox, J.; Hess, T.; Daccache, A.; Wheeler, T. Climate change impacts on crop productivity in Africa and South Asia. Environ. Res. Lett. 2012, 7, 034032. [CrossRef]

5. Rosenzweig, C.; Elliott, J.; Deryng, D.; Ruane, A.C.; Müller, C.; Arneth, A.; Boote, K.J.; Folberth, C.; Glotter, M.; Khabarov, N.; et al. Assessing agricultural risks of climate change in the 21st century in a global gridded crop model intercomparison. Proc. Natl. Acad. Sci. USA 2014, 111, 3268-3273. [CrossRef]

6. Lobell, D.B.; Gourdji, S.M. The influence of climate change on global crop productivity. Plant Physiol. 2012, 160, 1686-1697. [CrossRef]

7. Steenwerth, K.L.; Hodson, A.K.; Bloom, A.J.; Carter, M.R.; Cattaneo, A.; Chartres, C.J.; Hartfield, J.L.; Henry, K.; Hopmans, J.W.; Horwath, W.R.; et al. Climate-smart agriculture global research agenda: Scientific basis for action. Agric. Food Secur. 2014, 3, 11. [CrossRef]

8. Lipper, L.; McCarthy, N.; Zilberman, D.; Asfaw, S.; Branca, G. (Eds.) Climate Smart Agriculture: Building Resilience to Climate Change, 1st ed.; Springer: Cham, Switzerland, 2017; Volume 52.

9. Food and Agriculture Organization of the United Nations-FAO. Climate-Smart Agriculture and the Sustainable Development Goals: Mapping Interlinkages, Synergies and Trade-offs and Guidelines for Integrated Implementation; FAO: Rome, Italy, 2019.

10. Karlsson, L.; Naess, L.O.; Nightingale, A.; Thompson, J. 'Triple wins' or 'triple faults'? Analysing the equity implications of policy discourses on climate-smart agriculture (CSA). J. Peasant Stud. 2018, 45, 150-174. [CrossRef] 
11. Totin, E.; Segnon, A.C.; Schut, M.; Affognon, H.; Zougmoré, R.B.; Rosenstock, T.; Thornton, P.K. Institutional perspectives of climate-smart agriculture: A systematic literature review. Sustainability 2018, 10, 1990. [CrossRef]

12. Chandra, A.; McNamara, K.E.; Dargusch, P. Climate-smart agriculture: Perspectives and framings. Clim. Policy 2018, 18, 526-541. [CrossRef]

13. Alem, Y.; Eggert, H.; Ruhinduka, R. Improving welfare through climate-friendly agriculture: The case of the system of rice intensification. Environ. Resour. Econ. 2015, 62, 243-263. [CrossRef]

14. Siedenburg, J.; Martin, A.; McGuire, S. The power of "farmer friendly" financial incentives to deliver climate smart agriculture: A critical data gap. J. Integr. Environ. Sci. 2012, 9, 201-217. [CrossRef]

15. Fader, M.; Shi, S.; Bloh, W.V.; Bondeau, A.; Cramer, W. Mediterranean irrigation under climate change: More efficient irrigation needed to compensate for increases in irrigation water requirements. HESS 2016, 20, 953-973. [CrossRef]

16. Wollenberg, E.K. The mitigation pillar of Climate-Smart Agriculture (CSA): Targets and options. Agric. Dev. 2017, 30, 19-22.

17. Böttcher, H.; Freibauer, A.; Scholz, Y.; Gitz, V.; Ciais, P.; Mund, M.; Wutzler, T.; Schulze, E.D. Setting priorities for land management to mitigate climate change. Carbon Balance Manag. 2012, 7, 5. [CrossRef] [PubMed]

18. Lipper, L.; Thornton, P.; Campbell, B.M.; Baedeker, T.; Braimoh, A.; Bwalya, M.; Caron, P.; Cattaneo, A.; Garrity, D.; Henry, K.; et al. Climate-smart agriculture for food security. Nat. Clim. Chang. 2014, 4, 1068. [CrossRef]

19. Lipper, L.; Zilberman, D. A short history of the evolution of the climate smart agriculture approach and its Links to climate change and sustainable agriculture debates. In Climate Smart Agriculture; Springer: Cham, Switzerland, 2018.

20. Tranfield, D.; Denyer, D.; Smart, P. Towards a methodology for developing evidence-informed management knowledge by means of systematic review. Br. J. Manag. 2003, 14, 207-222. [CrossRef]

21. Berrang-Ford, L.; Pearce, T.; Ford, J.D. Systematic review approaches for climate change adaptation research. Reg. Environ. Chang. 2015, 15, 755-769. [CrossRef]

22. Reuters, T. Endnote $x 7$; Thomson Reuters: Philadelphia, PA, USA, 2013.

23. Long, T.B.; Blok, V.; Coninx, I. Barriers to the adoption and diffusion of technological innovations for climate-smart agriculture in Europe: Evidence from the Netherlands, France, Switzerland and Italy. J. Clean. Prod. 2016, 112, 9-21. [CrossRef]

24. McCarthy, N.; Lipper, L.; Branca, G. Climate-smart agriculture: Smallholder adoption and implications for climate change adaptation and mitigation. Mitig. Clim. Chang. Agric. Work. Pap. 2011, 3, 1-37.

25. Bogdanski, A. Integrated food-energy systems for climate-smart agriculture. Agric. Food Secur. $2012,1,9$. [CrossRef]

26. Neufeldt, H.; Jahn, M.; Campbell, B.M.; Beddington, J.R.; DeClerck, F.; De Pinto, A.; Gulledge, J.; Hellin, J.; Herrero, M.; Jarvis, A.; et al. Zougmoré. Beyond climate-smart agriculture: Toward safe operating spaces for global food systems. Agric. Food Secur. 2013, 2, 12. [CrossRef]

27. Harvey, C.A.; Chacón, M.; Donatti, C.I.; Garen, E.; Hannah, L.; Andrade, A.; Bede, L.; Brown, D.; Calle, A.; Chará, J.; et al. Climate-smart landscapes: Opportunities and challenges for integrating adaptation and mitigation in tropical agriculture. Conserv. Lett. 2014, 7, 77-90. [CrossRef]

28. Wright, H.; Vermeulen, S.; Laganda, G.; Olupot, M.; Ampaire, E.; Jat, M.L. Farmers, food and climate change: Ensuring community-based adaptation is mainstreamed into agricultural programmes. Clim. Dev. 2014, 6, 318-328. [CrossRef]

29. Peterson, C.A. Local-Level Appraisal of Benefits and Barriers Affecting Adoption of Climate-Smart Agricultural Practices: Ghana; CGIAR Research Program on Climate Change; Agriculture and Food Security (CCAFS): Copenhagen, Denmark, 2014.

30. Rosenstock, T.; Lamanna, C.; Arslan, A.; Richards, M. What is the scientific basis for climate-smart agriculture? Clim. Chang. Agric. Food Secur. 2015. Available online: http://www.ccardesa.org/knowledge-products/whatscientific-basis-climate-smart-agriculture (accessed on 2 February 2020).

31. Ampaire, E.L.; Happy, P.; van Asten, P.; Radeny, M. The Role of Policy in Facilitating Adoption of Climate-Smart Agriculture in Uganda; CGIAR Research Program on Climate Change; Agriculture and Food Security (CCAFS): Copenhagen, Denmark, 2015. 
32. Zougmoré, R.; Partey, S.; Ouédraogo, M.; Omitoyin, B.; Thomas, T.; Ayantunde, A.; Ericksen, P.; Said, M.; Jalloh, A. Toward climate-smart agriculture in West Africa: A review of climate change impacts, adaptation strategies and policy developments for the livestock, fishery and crop production sectors. Agric. Food Secur. 2016, 5, 26. [CrossRef]

33. Rosenstock, T.S.; Lamanna, C.; Chesterman, S.; Bell, P.; Arslan, A.; Richards, M.; Rioux, J.; Akinleye, A.O.; Champalle, C.; Cheng, Z.; et al. The Scientific Basis of Climate-Smart Agriculture: A Systematic Review Protocol; CCAFS Working Paper; CCAFS: Frederiksberg, Denmark, 2016; Volume 138, Available online: https://ccafs.cgiar.org/publications/scientific-basis-climate-smart-agriculture-systematicreview-protocol\#.XvDDLedRWUk (accessed on 2 February 2020).

34. Engel, S.; Muller, A. Payments for environmental services to promote "climate-smart agriculture"? Potential and challenges. J. Agric. Econ. 2016, 47, 173-184. [CrossRef]

35. Khatri-Chhetri, A.; Aggarwal, P.K.; Joshi, P.K.; Vyas, S. Farmers' prioritization of climate-smart agriculture (CSA) technologies. Agric. Syst. 2017, 151, 184-191. [CrossRef]

36. Lee, J. Farmer participation in a climate-smart future: Evidence from the Kenya Agricultural Carbon Project. Lands Use Policy 2017, 68, 72-79. [CrossRef]

37. Sain, G.; Loboguerrero, A.M.; Corner-Dolloff, C.; Lizarazo, M.; Nowak, A.; Martínez-Barón, D.; Andrieu, N. Costs and benefits of climate-smart agriculture: The case of the Dry Corridor in Guatemala. Agric. Syst. 2017, 151, 163-173. [CrossRef]

38. Andrieu, N.; Sogoba, B.; Zougmore, R.; Howland, F.; Samake, O.; Bonilla-Findji, O.; Lizarazo, M.; Nowak, A.; Dembele, C.; Corner-Dolloff, C.; et al. Prioritizing investments for climate-smart agriculture: Lessons learned from Mali. Agric. Syst. 2017, 154, 13-24. [CrossRef]

39. Westermann, O.; Förch, W.; Thornton, P.; Körner, J.; Cramer, L.; Campbell, B. Scaling up agricultural interventions: Case studies of climate-smart agriculture. Agric. Syst. 2018, 165, 283-293. [CrossRef]

40. Senyolo, M.P.; Long, T.B.; Blok, V.; Omta, O. How the characteristics of innovations impact their adoption: An exploration of climate-smart agricultural innovations in South Africa. J. Clean. Prod. 2018, 172, 3825-3840. [CrossRef]

41. Scherr, S.J.; Shames, S.; Friedman, R. From climate-smart agriculture to climate-smart landscapes. Agric. Food Secur. 2012, 1, 12. [CrossRef]

42. Dougill, A.J.; Whitfield, S.; Stringer, L.C.; Vincent, K.; Wood, B.T.; Chinseu, E.L.; Steward, P.; Mkwambisi, D.D. Mainstreaming conservation agriculture in Malawi: Knowledge gaps and institutional barriers. J. Environ. Manag. 2017, 195, 25-34. [CrossRef] [PubMed]

43. Brandt, P.; Kvakić, M.; Butterbach-Bahl, K.; Rufino, M.C. How to target climate-smart agriculture? Concept and application of the consensus-driven decision support framework "targetCSA". Agric. Syst. 2018, 151, 234-245. [CrossRef]

44. Scherer, L.; Verburg, P.H. Mapping and linking supply-and demand-side measures in climate-smart agriculture. A review. Agron. Sustain. Dev. 2017, 37, 66. [CrossRef]

45. Makate, C. Effective scaling of climate smart agriculture innovations in African smallholder agriculture: A review of approaches, policy and institutional strategy needs. Environ. Sci. Policy. 2019, 96, 37-51. [CrossRef]

46. Millar, J.; Connell, J. Strategies for scaling out impacts from agricultural systems change: The case of forages and livestock production in Laos. Agric. Human Values 2010, 27, 213-225. [CrossRef]

47. European Commission. Communication from the Commission to the European Parliament, the Council, the European Economic and Social Committee and the Committee of the Regions-The Future of Food and Farming; European Commission: Brussels, Belgium, 2017.

48. CORDIS. Precision Farming: Sowing the Seeds of a New Agricultural Revolution; European Commission: Brussels, Belgium, 2017; Available online: https://cordis.europa.eu/article/id/400295-precision-farming-sowing-theseeds-of-a-new-agricultural-revolution (accessed on 16 September 2019).

49. ISTAT. Andamento Dell'Economia Agricola, Roma, Report. 2019. Available online: https://www.istat.it/it/ files//2020/05/Andamento-economia-agricola-2019.pdf (accessed on 30 March 2020).

50. Eurostat. Agriculture, Forestry and Fishery Statistics; Publications Office of the EU: Luxembourg, 2019. Available online: https://ec.europa.eu/eurostat/web/products-statistical-books/-/KS-FK-19-001 (accessed on 30 March 2020). 
51. Papadopoulos, A.G.; Fratsea, L.M.; Karanikolas, P.; Zografakis, S. Reassembling the Rural: Socio-Economic Dynamics, Inequalities and Resilience in Crisis-Stricken Rural Greece. Sociol. Ruralis. 2019, 59, 474-493. [CrossRef]

52. Schaafsma, M.; Utila, H.; Hirons, M.A. Understanding trade-offs in upscaling and integrating climate-smart agriculture and sustainable river basin management in Malawi. Environ. Sci. Policy 2018, 80, 117-124. [CrossRef]

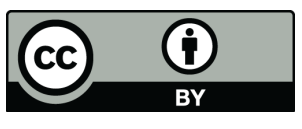

(C) 2020 by the authors. Licensee MDPI, Basel, Switzerland. This article is an open access article distributed under the terms and conditions of the Creative Commons Attribution (CC BY) license (http://creativecommons.org/licenses/by/4.0/). 